\title{
CpG hypermethylation of collagen type I a 2 contributes to proliferation and migration activity of human bladder cancer
}

\author{
KATSUHISA MORI ${ }^{1}$, HIDEKI ENOKIDA ${ }^{1}$, ICHIRO KAGARA ${ }^{1}$, KAZUMORI KAWAKAMI ${ }^{1}$, \\ TAKESHI CHIYOMARU ${ }^{1}$, SHUICHI TATARANO ${ }^{1}$, KAZUYA KAWAHARA ${ }^{2}$, \\ KENRYU NISHIYAMA ${ }^{1}$, NAOHIKO SEKI ${ }^{3}$ and MASAYUKI NAKAGAWA ${ }^{1}$ \\ ${ }^{1}$ Department of Urology, Graduate School of Medical and Dental Sciences, Kagoshima University; \\ ${ }^{2}$ Kawahara Nephro-urology Clinic, Kagoshima; ${ }^{3}$ Department of Functional Genomics, \\ Graduate School of Medicine, Chiba University, Chiba, Japan
}

Received December 29, 2008; Accepted March 3, 2009

DOI: 10.3892/ijo_00000289

\begin{abstract}
In our microarray screening of methylated genes in bladder cancer (BC), the collagen type 1 a 2 (COL1A2) gene was the most up-regulated among the 30,144 genes screened. We hypothesize that inactivation of the COL1A2 gene through $\mathrm{CpG}$ methylation contributes to proliferation and migration activity of human $\mathrm{BC}$. We subjected a bladder cancer cell line (BOY) and 67 BC specimens and 10 normal bladder epitheliums (NBEs) to conventional or real-time methylation quantitative polymerase chain reaction (PCR) and to real-time reverse transcriptase (RT)-PCR. We also established a stable COL1A2 transfectant for evaluating cell proliferation and migration activity. After 5-aza-dC treatment, the expression levels of COL1A2 mRNA transcript markedly increased in BOY. Our cell proliferation assays consistently demonstrated growth inhibition in the COL1A2 transfectant compared with control and wild-type BOY cells $(\mathrm{p}<0.0001)$. Wound healing assays also showed significant wound healing inhibition in the COL1A2 transfectant compared to the counterparts $(\mathrm{p}=0.0016)$. We demonstrated by bisulfite DNA sequencing that the promoter hypermethylation of COL1A2 was a frequent event in clinical BCs. The methylation index of COL1A2 was significantly higher in the $67 \mathrm{BCs}$ than in the 10 NBEs ( $\mathrm{p}=0.0011)$. Conversely, COL1A2 mRNA transcript was significantly lower in the BCs than in the NBEs $(p=0.0052)$. The mechanism of COL1A2 down-regulation in $\mathrm{BC}$ is through $\mathrm{CpG}$ hypermethylation of the promoter region. COL1A2 gene inactivation through $\mathrm{CpG}$ hypermethylation may contribute to proliferation and migration activity of $\mathrm{BC}$.
\end{abstract}

Correspondence to: Dr Hideki Enokida, Department of Urology, Graduate School of Medical and Dental Sciences, Kagoshima University, 8-35-1 Sakuragaoka, Kagoshima 890-8520, Japan

E-mail: enokida@m.kufm.kagoshima-u.ac.jp

Key words: microarray, collagen type $1 \alpha 2$, bladder cancer, methylation

\section{Introduction}

Bladder cancer (BC), one of the five most common malignancies in the United States, is the 2nd most common tumor of the genitourinary tract and the 2nd most common cause of death in patients with urinary tract malignancies (1). As in other human cancers, loss of function of tumor suppressor genes and activation of oncogenes are two major alterations that promote $\mathrm{BC}$ initiation and progression (2). Recent intensive study of the epigenetic change of gene promoter hypermethylation has shown that it is an important molecular mechanism contributing to tumor suppressor gene inactivation in human cancer (3). There are numerous methods for large-scale screening for the detection of methylated genes in the human genome $(4,5)$. However, most of them are technically complex (6). Our laboratory has developed a simple technique that combines microarray data from BC specimens with those from $\mathrm{BC}$ cells treated with pharmacological demethylating agent (5-aza-dC) (7). In this study, we used for the first time this combination analysis and identified 24 candidate hypermethylated genes. Among these genes, collagen type I 2 (COL1A2) gene was identified as the most up-regulated one.

Collagen type I, the most abundant molecule within the collagen family, consists of a heterotrimer with two $\alpha 1$ chains and one $\alpha 2$ chain. It is ubiquitous in skin, bone, tendon, dentin, etc (8). This type of collagen represents the major fibrillar component of the stroma in most solid malignancies, such as hepatoma, malignant melanoma and colorectal cancer (9-11). A particular extracellular matrix in stroma is necessary for the growth of tumors. The components of this matrix, in particular collagen type I, can be produced by both tumor cells and stromal fibroblast cells $(11,12)$. In general, cancer cells producing type I collagen tend to have low tumorigenic potential (11-17). However, in some aggressive tumors, collagen type I is overexpressed and plays a role in tumor development $(18,19)$. Thus, the functional role of collagen type I remains controversial and studies for collagen type I in $\mathrm{BC}$ are lacking in the literature. In this study, we evaluated the methylation status of $C O L 1 A 2$ promoter and the expression of COL1A2 mRNA in clinical BCs. Moreover, we established 
COL1A2 transfectant and compared its proliferation and migration activity with those of the parental $\mathrm{BC}$ cells.

\section{Materials and methods}

Tissue samples. Tissue specimens were collected from $67 \mathrm{BC}$ patients who had undergone radical cystectomy or transurethral resection of BC (TUR-Bt) at Kagoshima University Hospital between 2000 and 2005. Also used were 10 normal bladder epithelium (NBE) samples from patients with prostate cancer who had undergone radical prostatectomy. The background of patients is summarized in Table I. Of the 67 patients, seven were lost to follow-up. Written prior informed consent was obtained from all patients for use of their samples and clinical and pathological data. Each tumor was staged in accordance with the tumor-node-metastasis (TNM) staging system (20). A total of 77 fresh tissue samples [67 BCs and 10 normal bladder epitheliums (NBEs)] were frozen and stored at $-80^{\circ} \mathrm{C}$ until being processed for DNA and RNA extraction.

Cell culture and 5-aza-dC treatment. The BC cell lines, KK47, T24, UMUC and BOY, which were established in our laboratory were maintained in minimum essential medium supplemented with $10 \%$ fetal calf serum and L-glutamine in a humidified atmosphere of $5 \% \mathrm{CO}_{2}$ and $95 \%$ air at $37^{\circ} \mathrm{C}(21)$. To screen for epigenetic alterations of gene methylation, the BOY cells were treated with the demethylating agent 5 -aza-dC $(1 \mu \mathrm{M})$. Cultured cells were harvested after four days of exposure to 5-aza-dC and the RNA was extracted.

Nucleic acid extraction. Genomic DNA from the BCs and NBEs was extracted with QIAamp tissue kits (Qiagen, Valencia, CA) after the microdissection of $10-\mu \mathrm{m}$-thick paraffin-embedded sections and was precipitated with ethanol. The total RNA was isolated from the frozen fresh tissues and BOY cells with Isogen (Nippon Gene, Tokyo, Japan) following the manufacturer's protocol. The concentrations of DNA and RNA were determined spectrophotometrically; their integrity was verified by gel electrophoresis. The RNA quality was checked in BioPhotometer ${ }^{\mathrm{TM}}$ (Eppendorf, Tokyo, Japan).

Antisense RNA (aRNA) amplification. We amplified aRNA from $5 \mu \mathrm{g}$ of total RNA using the Amino Allyl MessageAmp ${ }^{\mathrm{TM}}$ aRNA amplification kit (Ambion, Austin, TX). We amplified single-stranded cDNA using an oligo-dT primer bearing a T7 promoter, converted the product into double-stranded cDNA, purified this cDNA and then performed amplification from double-stranded cDNA templates following the manufacturer's protocol.

Dye coupling and microarray hybridization. Oligoarrays (AceGene ${ }^{\circledR}$ Human Oligo Chip 30K (http://hitachisoft.jp/ dnasis/ex_acegene/index.html), Hitachi Software Engineering Co. Ltd., Yokohama, Japan) spotted with 30,144 genes were used for dye coupling, for BOY study before (Cy3) and after (Cy5) 5-aza-dC treatment and for microarray hybridization. Pellets were formed with ethanol-precipitated aRNA $(5 \mu \mathrm{g})$ and $5 \mu 1$ of $\mathrm{CyDye}^{\mathrm{TM}}$ (GE Healthcare Bio-Sciences, Buckinghamshire, UK); $5 \mathrm{X}$ fragmentation buffer was added after purification. After further refinement, we obtained concentrated
Table I. Patient characteristics.

\begin{tabular}{|c|c|}
\hline $\begin{array}{l}\text { Bladder cancer }(\mathrm{BC}) \\
\text { Total number }\end{array}$ & 67 \\
\hline Median age (range) & $72.6(40-100)$ years \\
\hline $\begin{array}{l}\text { Gender } \\
\text { Male } \\
\text { Female }\end{array}$ & $\begin{array}{l}53 \\
14\end{array}$ \\
\hline $\begin{array}{l}\text { Stage } \\
\text { Tis } \\
\text { Superficial (pTa) } \\
\text { Invasive ( } \geq \text { pT1) } \\
\text { Unknown }\end{array}$ & $\begin{array}{r}2 \\
13 \\
44 \\
8\end{array}$ \\
\hline $\begin{array}{l}\text { Grade } \\
\text { G1 } \\
\text { G2 } \\
\text { G3 }\end{array}$ & $\begin{array}{r}5 \\
32 \\
30\end{array}$ \\
\hline $\begin{array}{l}\text { Operation } \\
\text { Cystectomy } \\
\text { TUR-Bt }\end{array}$ & $\begin{array}{r}8 \\
59\end{array}$ \\
\hline $\begin{array}{l}\text { Pre-treatment } \\
\text { TUR-Bt } \\
\text { Chemotherapy } \\
\text { BCG }\end{array}$ & $\begin{array}{l}5 \\
2 \\
1\end{array}$ \\
\hline $\begin{array}{l}\text { Recurrence } \\
\text { Recurrence (+) } \\
\text { Recurrence (-) }\end{array}$ & $\begin{array}{l}19 \\
41\end{array}$ \\
\hline Follow-up period (range) & 476 (5-1440) days \\
\hline $\begin{array}{l}\text { Normal bladder epithelium (NBE) } \\
\text { Total number }\end{array}$ & 10 \\
\hline Median age (range) & $66(58-77)$ years \\
\hline $\begin{array}{l}\text { Gender } \\
\text { Male } \\
\text { Female }\end{array}$ & $\begin{array}{r}10 \\
0\end{array}$ \\
\hline
\end{tabular}

coupled aRNA. A hybridization solution was added to the microarrays and this was followed by 18 -h incubation at $50^{\circ} \mathrm{C}$.

cDNA preparation and conventional RT-PCR. We synthesized first-strand cDNA with $1 \mu \mathrm{g}$ of total RNA using oligo-dT primers of the reverse transcription (RT) system (Promega, Tokyo, Japan). For conventional RT-PCR, glyceraldehyde-3phosphate dehydrogenase (GAPDH) was the internal control. The primer sequences and RT-PCR conditions are listed in Table II. The PCR products were electrophoresed on $2.0 \%$ agarose gels.

Real-time quantitative RT-PCR. Gene-specific PCR products were assayed continuously using a 7900 real-time PCR system (Applied Biosystems, Foster City, CA) following the manufacturer's protocol. The initial PCR step was a 10-min hold at $95^{\circ} \mathrm{C}$; the cycles $(\mathrm{n}=40)$ consisted of a 15 -sec denaturation step at $95^{\circ} \mathrm{C}$ followed by a 1-min annealing/ extension step at $63^{\circ} \mathrm{C}$. All reactions were performed in 
Table II. Primer sequence and PCR conditions.

\begin{tabular}{|c|c|c|c|}
\hline & Primer sequence $\left(5^{\prime}-3^{\prime}\right)$ & $\begin{array}{l}\text { Product size } \\
\text { (bp) }\end{array}$ & $\begin{array}{l}\text { Annealing } \\
\text { temperature, } \\
\text { time (cycle) }\end{array}$ \\
\hline \multicolumn{4}{|c|}{ Conventional RT-PCR } \\
\hline COL1A2-sense & GGAGCTCCAAGGACAAGAAA & 118 & $58^{\circ} \mathrm{C}, 30 \sec (35)$ \\
\hline COL1A2-antisense & ATGAAGGCAAGTTGGGTAGC & & \\
\hline G3PDH-sense & GAAGGTGAAGGTCGGAGTCA & 255 & $55^{\circ} \mathrm{C}, 30 \sec (26)$ \\
\hline G3PDH-antisense & CACTTGATTTTGGAGGGATCTC & & \\
\hline \multicolumn{4}{|c|}{ Conventional MSP (COL1A2) } \\
\hline Pan-sense & GAGATTTGTAAATTTTGTTTATGT & 161 & $48^{\circ} \mathrm{C}, 60 \sec (45)$ \\
\hline Pan-antisense & TAAACACTTTTAAAACTTTCAAAAAA & & \\
\hline MSP-sense & GGGTTGTAGAGTATTTCGACG & 101 & $55^{\circ} \mathrm{C}, 30 \mathrm{sec}(40)$ \\
\hline MSP-antisense & ACTCGTTATCTACATACCTCCG & & \\
\hline USP-sense & GGGTTGTAGAGTATTTTGATGTGT & 101 & $55^{\circ} \mathrm{C}, 30 \mathrm{sec}(40)$ \\
\hline USP-antisense & CTAАСТCATTATCTACATACCTCCA & & \\
\hline \multicolumn{4}{|c|}{ Real-time QMSP (COL1A2) } \\
\hline QMSP-sense & GGGTTGTAGAGTATTTCGACG & 101 & $55^{\circ} \mathrm{C}, 60 \mathrm{sec}(45)$ \\
\hline QMSP-antisense & ACTCGTTATCTACATACCTCCG & & \\
\hline Probe & TTAAATTTGGAAAGGGCG & & \\
\hline \multicolumn{4}{|c|}{ Real-time QMSP (MYOD1) } \\
\hline QMSP-sense & ATTTATGTGGTGGGTGGATTTTGGT & 117 & $55^{\circ} \mathrm{C}, 60 \mathrm{sec}(45)$ \\
\hline QMSP-antisense & АТССССТСТСТАТССССААСС & & \\
\hline Probe & ТСССТТССТАТТССТАААТССААССТАААТАССТСС & & \\
\hline
\end{tabular}

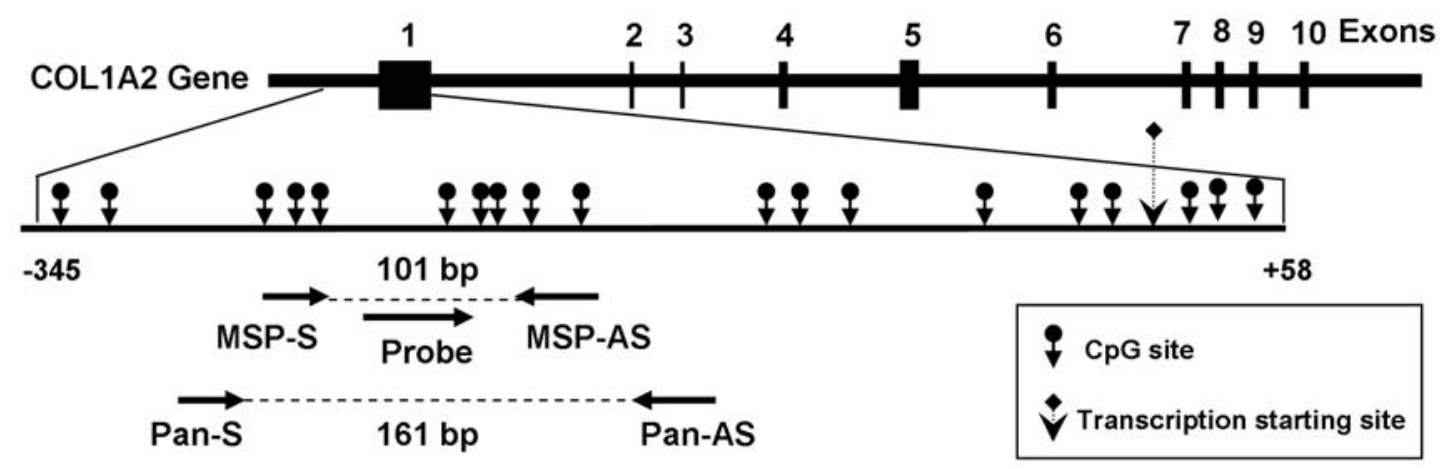

Figure 1. Schematic representation of the location of $\mathrm{CpG}$ sites and primers designed within the functional promoter of the COL1A2 gene. First, universal PCR was performed with the universal primers Pan-sense (S) and Pan-antisense (AS), which do not carry any CpG sites. Conventional MSP and USP were with primer sets MSP-S and MSP-AS, and USP-S and USP-AS, respectively, and the universal PCR product was used as a template. For TaqMan quantitative methylation-specific PCR (QMSP), the fluorescent probe and primer sets were designed to hybridize to the amplified DNA region.

triplicate and a negative control lacking cDNA was included. For quantitative analysis, Glucuronidase $\beta($ GUSB) was used as an internal control because it had shown the smallest $\mathrm{Cy} 5 / \mathrm{Cy} 3$ fluctuation in our microarray analysis. The relative mRNA expression examined was normalized to the amount of GUSB in the same cDNA using the standard-curve method provided by the manufacturer. For TaqMan probes and primers for COL1A1/COL1A2 and GUSB, we used assay-ondemand gene expression products (Applied Biosystems). For normal bladder controls we prepared cDNA samples from 2 different lots of human bladder total RNA (Chemicon International, Inc., Temecula, CA, USA). All reactions were performed in duplicate.
Conventional methylation-specific PCR. Genomic DNA $(100 \mathrm{ng})$ from $\mathrm{BCs}$ and NBEs was subjected to sodium bisulfite modification using the CpGenome ${ }^{\mathrm{TM}}$ DNA modification kit (Millipore, Billerica, MA). According to the promoter information of COL1A2 (22), methylation-specific (MSP) and unmethylation-specific (USP) primers were designed based on the functional promoter sequence using MethPrimer software (http://www.urogene.org/methprimer). An initial PCR product was created with universal primers (Pan-S and Pan-AS), of which the forward and reverse primers carry no CpG sites; this was followed by a second nested PCR with primers specific for MSP or USP (Fig. 1). The primer sequences and PCR conditions are listed in Table II. In each 
assay, the absence of a DNA template served as the negative control. The obtained MSP and USP products were analyzed by electrophoresis in $2 \%$ agarose gels.

Real-time quantitative methylation-specific PCR. For TaqMan quantitative methylation-specific PCR (QMSP), the fluorescent probe and primer sets were designed to also hybridize to the amplified region of DNA (Fig. 1). Myogenic differentiation-1 (MYOD1) primer sequences were used as an internal control. The first PCR was amplified with universal primers (Pan-S and Pan-AS) using $3 \mu \mathrm{l}$ of bisulfite-treated DNA in a total volume of $20 \mu \mathrm{l}$. The first PCR step consisted of initial denaturation $\left(10 \mathrm{~min}, 95^{\circ} \mathrm{C}\right)$ followed by 15 cycles of a 1-min denaturation step at $95^{\circ} \mathrm{C}$, an annealing step at $48^{\circ} \mathrm{C}$ and an extension step at $72^{\circ} \mathrm{C}$. A second round of nested QMSP was then carried out using $1 \mu 1$ of the first PCR product. The PCR cycle was programmed up to 45 cycles and all reactions were performed in duplicate. The primers and probe sequences are listed in Table II. Serial dilutions of CpGenome universal methylated DNA (Millipore, Tokyo, Japan) were used to construct a calibration curve. The methylation index was defined as the quantity of fluorescence intensity derived from COL1A2 promoter amplification divided by the fluorescence intensity from MYOD1 amplification, multiplied by 1000 .

Bisulfite DNA sequencing analysis. Bisulfite-modified DNA was amplified using a pair of universal primers (Pan-S and Pan-AS) in a total volume of $20 \mu 1$. The PCR conditions are shown in Table II. Direct bisulfite DNA sequencing of the PCR products using a forward Pan-S primer was carried out following the manufacturer's instructions (Applied Biosystems).

Construction of COL1A2 expression vectors and transfection to $B O Y$. The $C O L 1 A 2$ vector was constructed by inserting fulllength $C O L 1 A 2$ cDNA into the $\mathrm{XbaI}$ and BamHI restriction site of the pBApo-CMV Neo ${ }^{\mathrm{TM}}$ vector (Takara Bio, Otsu, Japan). The COL1A2- and the non-targeting (control) vector were transfected into BOY cells by calcium phosphate coprecipitation. The BOY cells were split and grown in selective medium with $1000 \mathrm{mg} / 1$ of G418. After 2 weeks, G418resistant colonies were chosen and expanded in medium containing $100 \mathrm{mg} / \mathrm{l}$ of G418.

Immunoblotting. Total protein lysate was prepared with detergent lysis buffer in the presence of a protease inhibitor. The $20 \mu \mathrm{g}$ of protein lysate was separated by NuPAGE on 4-12\% bis-tris gel (Invitrogen, Tokyo) and transferred into a polyvinylidene fluoride (PVDF) membrane. Immunoblotting was done with diluted (1:1000) polyclonal COL1A2 antibody (sc-8786, Santa Cruz Biotechnology, Santa Cruz, CA). After being washed, the membrane was incubated with donkey anti-goat IgG horseradish peroxidase conjugate (Bio-Rad, Hercules, CA). Specific complexes were visualized with an echochemiluminescence detection system (GE Healthcare Bio-Sciences).

Immunocytochemistry. For COL1A2 immunostaining we used cell monolayers grown $\left(48 \mathrm{~h}, 37^{\circ} \mathrm{C}, 5 \% \mathrm{CO}_{2}\right)$ on poly-L-lysinecoated chamber glass (Asahi Techno Glass Corp., Tokyo,
Japan), rinsed once with phosphate-buffered saline (PBS), and treated sequentially for 3 min each with 70-, 90- and 100\% acetone at $-20^{\circ} \mathrm{C}$. After $30-\mathrm{min}$ immersion in blocking buffer [0.01 M PBS (1.0 l) + goat serum $(20 \mathrm{ml})+$ Triton-X $(2 \mathrm{ml})+$ bovine serum albumin $(1.0 \mathrm{~g})]$, we added polyclonal antibody for COL1A2 (sc-8786; 1:500 dilution) overnight. Immuno-staining was visualized with fluorescein isothiocyanate (FITC)-labeled second antibody (\#111-096-003, Jackson Immuno Research) and photographed with an all-inone digital microscope (Keyence Japan, Osaka, Japan). For the control, all experiments were performed without the primary antibody.

3-(4,5-dimethyl-thiazol-2-yl)-2,5-diphenyltetrazolium bromide (MTT) assays. COL1A2 transfectant, control and wild-type BOY cells were seeded at a density of 10,000 cells/well in 96-well microplates and incubated for 24, 48, 72, 96 or $120 \mathrm{~h}$. Then, $50 \mu 1$ of $1-\mathrm{mg} / \mathrm{ml}$ MTT in PBS were added to each well and the plates were incubated for an additional $4 \mathrm{~h}$. The resulting formazan was dissolved with $100 \mu 1$ of dimethylsulfoxide (DMSO) after aspiration of the culture medium. The plates were placed on a plate shaker for $5 \mathrm{~min}$ and read immediately at $570 \mathrm{~nm}$ using a microplate reader (MPR-A4i; Tosho, Tokyo, Japan).

Wound healing assay. COL1A2 transfectant, control, and wild-type BOY cells were used in the 'wound healing' assay to test the alteration of cell motility and migration. Cells were initially seeded uniformly onto 60 -mm culture plates with an artificial 'wound' carefully created at $0 \mathrm{~h}$. A P-20 pipette tip was used to scratch the subconfluent cell monolayer. Microphotographs were taken at 0,6 and $12 \mathrm{~h}$. Quantitative analysis of the percentage of wound healing was calculated using the distance across the wound $(\mathrm{n}=20)$ at 0,6 and $12 \mathrm{~h}$, divided by the distance measured at $0 \mathrm{~h}$ for each cell line.

Collagen analysis. Collagen was extracted from conditioned medium by pepsin digestion and separated by repeated salt fractionation, as described previously (10). The concentration of $\mathrm{NaCl}$ is $0.7 \mathrm{M}$ and purified collagen was analyzed by sodium dodecyl sulfate poly-acrylamide gel electrophoresis (SDS-PAGE) using 2-15\% gradient gel. Human Collagen Type $I^{\circledR}$ (Applied Cell Biotechnologies, Yokohama, Japan) was used as a positive control for distinguishing $\alpha 1$ - from $\alpha 2$ chain of type I collagen.

Statistical analysis and annotation of gene function. The relationship between two groups and the numerical value obtained by real-time RT-PCR was analyzed using the Mann-Whitney $U$ test. The relationships between three groups and the numerical value were analyzed using the Bonferroniadjusted Mann-Whitney U test. The analysis software was Expert StatView (version 4, SAS Institute Inc., Cary, NC); for the comparison test among the three groups, the non-adjusted statistical level of significance of $\mathrm{p}<0.05$ corresponds to a Bonferroni-adjusted level of $\mathrm{p}<0.0167$. The molecular functions of the up-regulated genes after 5-aza-dC treatment were referenced using Gene Ontology (http://www.gene ontology.org/) and GeneCards (http://www.genecards.org/ index.shtml). 

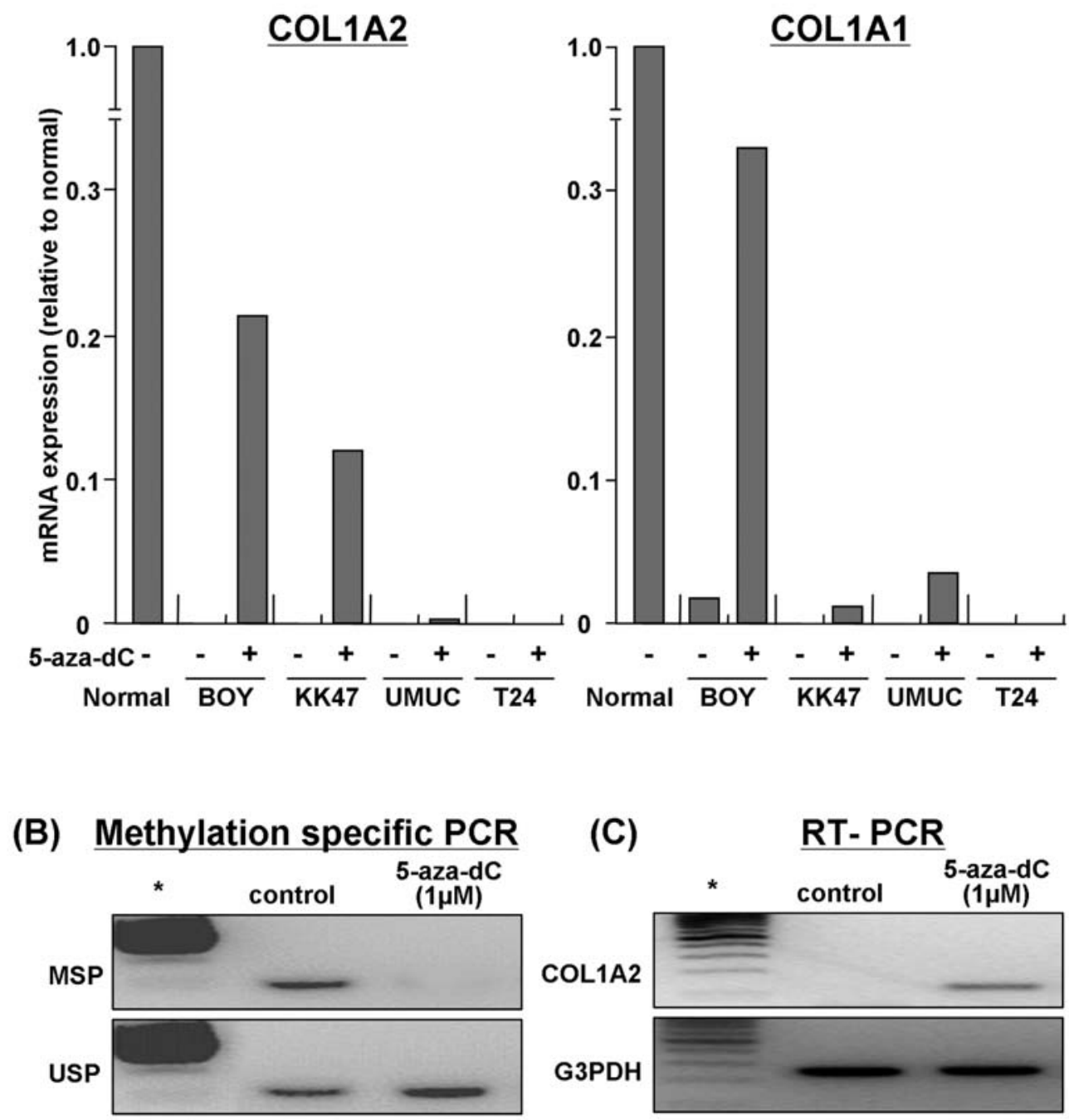

Figure 2. COL1A1/COL1A2 mRNA expression in BC cells before and after treatment with 5-aza-dC (A). Methylation-specific PCR (MSP) (B) and conventional RT-PCR (C) demonstrated that promoter hypermethylation of COL1A2 gene was markedly decreased and that the mRNA transcript of the COL1A2 gene was markedly increased after 5-aza-dC treatment in BOY cells. PCR conditions and primer sequences are described in Table II. *100 bp DNA ladder.

\section{Results}

Identification of genes up-regulated in 5-aza-dC-treated BOY cells. Among the 30,144 genes, we identified 24 that were up-regulated $>1.5$-fold in 5 -aza-dC-treated compared to untreated BOY cells by filtering the down-regulated genes in the BCs used in our previous microarray (7) (Table III). Among these, 15 harbored $\mathrm{CpG}$ islands in their putative promoter regions. Among the 24 candidate genes, we focused on COL1A2 and COL1A1 because these genes are the top 2 up-regulated one (6.01- and 4.03-fold) of all the 24 genes tested.

Verification of altered COL1A2 and COL1A1 $\mathrm{mRNA}$ expression in $B C$ cells before and after treatment of 5-aza-dC and methylation status of the COL1A2 gene promoter. Four BC cell lines (BOY, KK47, UMUC and T24) were subjected to real-time RT-PCR to evaluate the mRNA expression levels of COL1A2 and COL1A1 (Fig. 2A). Before 5-aza-dC treatment, no mRNA expression of COL1A2 was observed, but we found certain expression levels of COL1A1 in BOY cells. In contrast, marked expression was observed in normal human bladder RNA. After 5-aza-dC treatment, COL1A2 and COL1A1 mRNA expression was overwhelmingly increased especially in BOY cells, which had been subjected to cDNA microarray analysis mentioned above. We found no retrieval of the mRNA expression in T24 cells. Therefore, we selected BOY cells for further experiments. The MSP and USP assays for $C O L 1 A 2$ for the BOY cells before and after treatment with 5-aza-dC are shown in Fig. 2B. Treatment with 5-aza-dC eliminated the MSP-positive band in BOY cells (Fig. 2B). Conventional RT-PCR also demonstrated that the expression level of COL1A2 mRNA transcripts was markedly increased in BOY cells treated with 5-aza-dC $(1 \mu \mathrm{M})$ compared to that of the untreated control (Fig. 2C).

Identification of COL1A2 expression in transfected cells and effect of COL1A2 overexpression on cell growth. Because we found no mRNA expression of COL1A2 in wild-type BOY cells and marked retrieval of the gene expression after the 


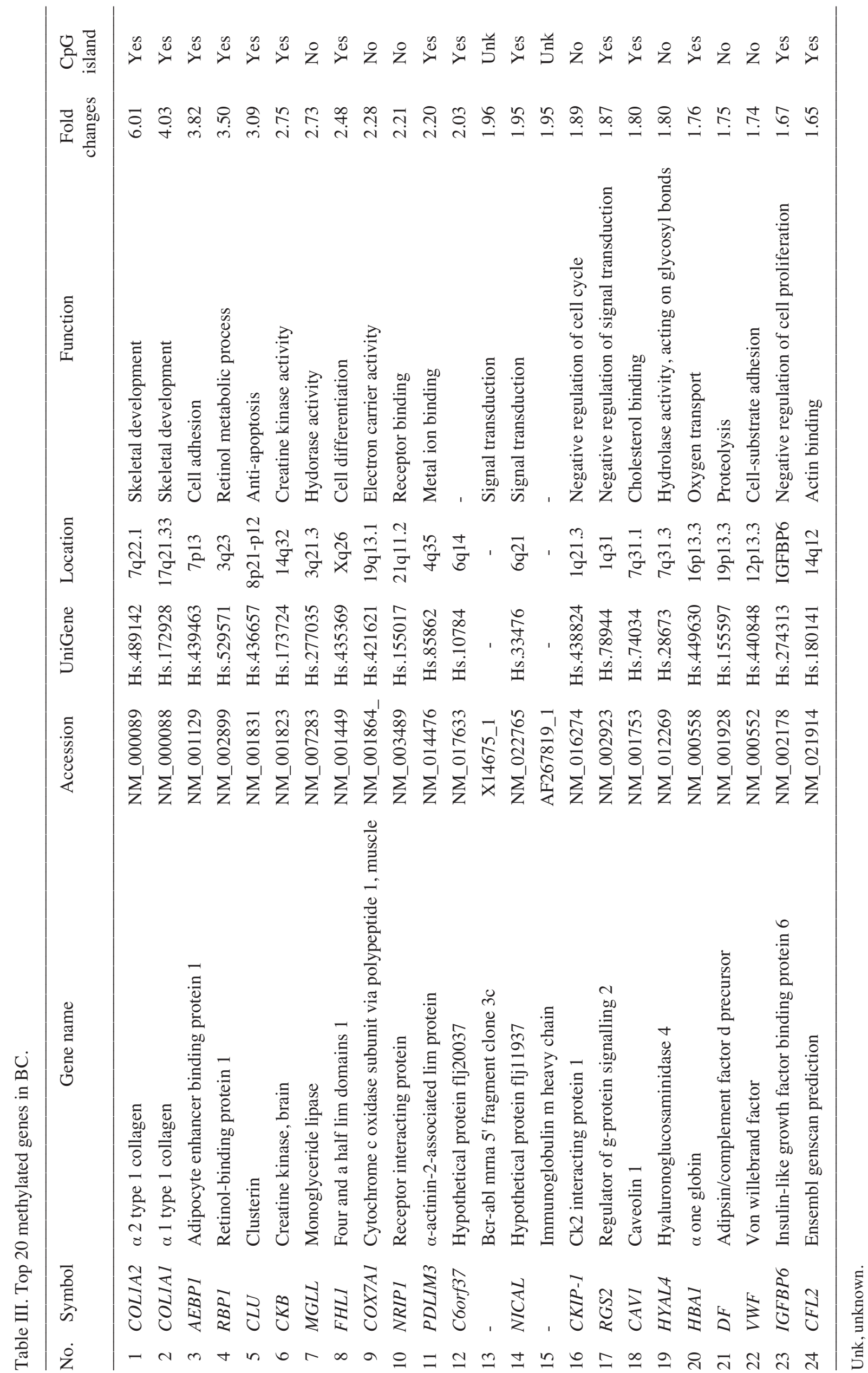


(A)

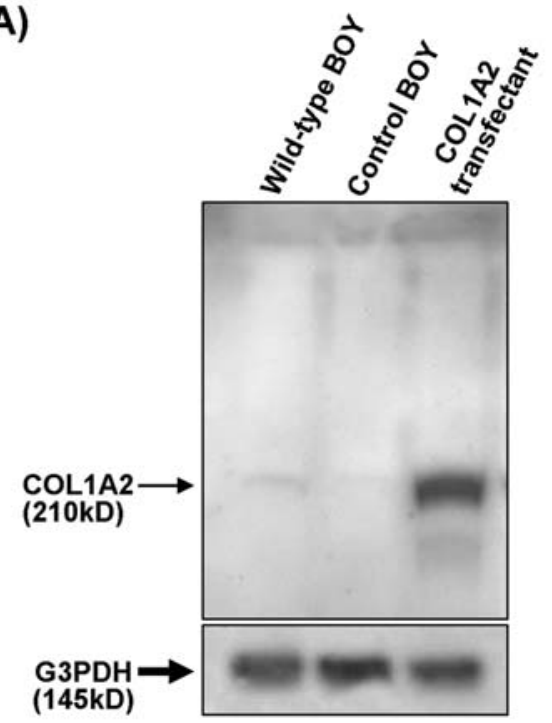

(B)

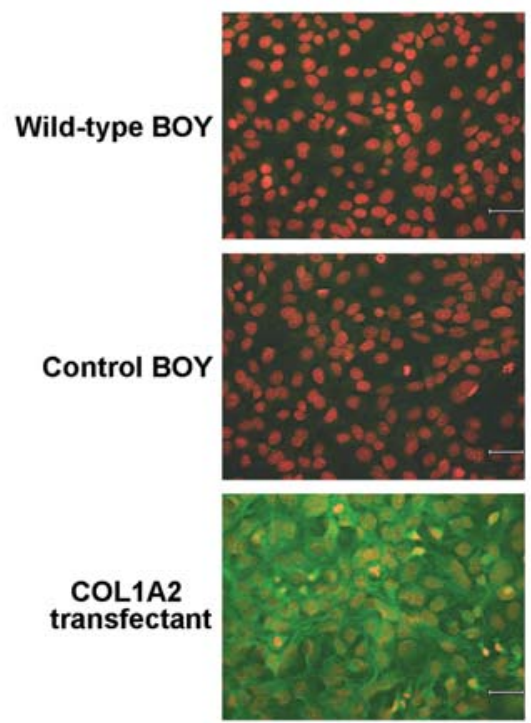

(C)

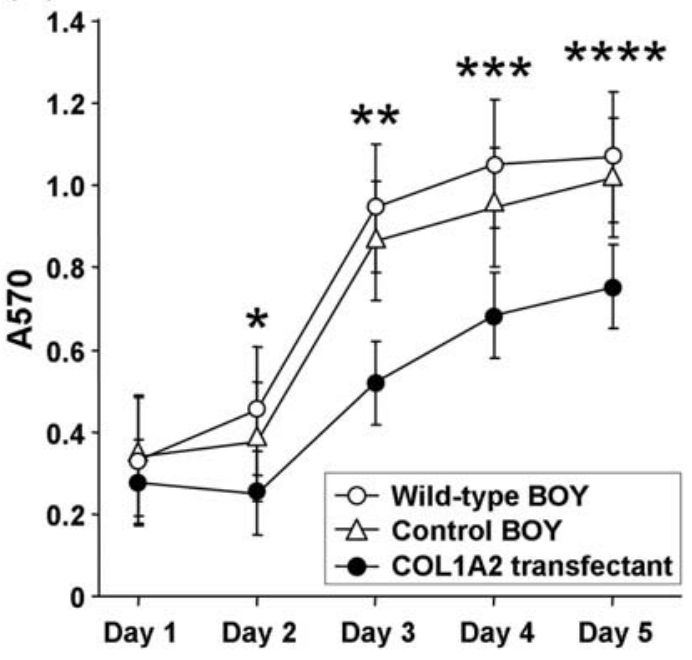

(D)

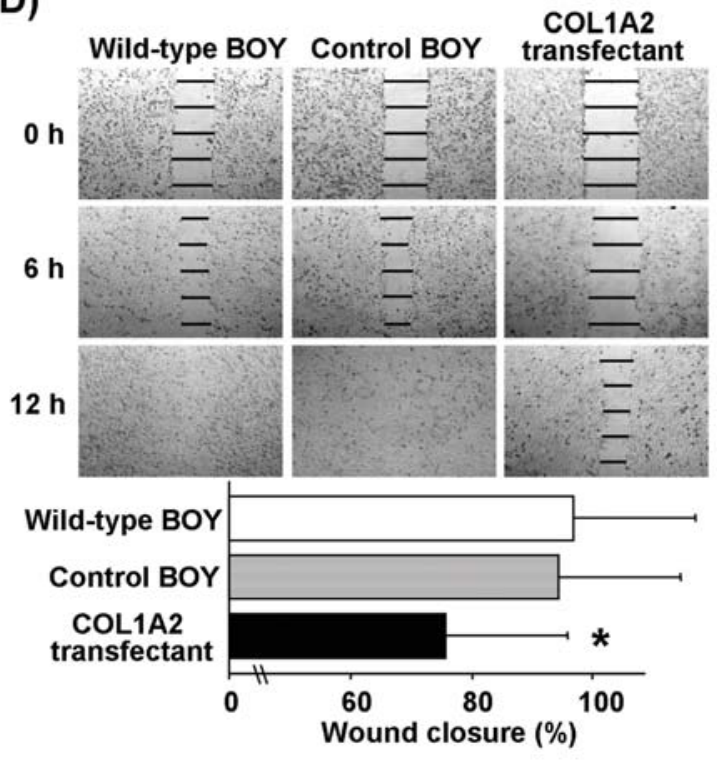

Figure 3. Effect of COL1A2 transfection on the growth of BOY cells. (A) COL1A2 expression determined by immunoblotting. Lane 1, wild-type BOY cells; lane 2, cells treated with the control vector; lane 3, COL1A2-transfected BOY cells. (B) COL1A2 protein expression visualized by immunocytochemistry. In the COL1A2 transfectant, COL1A2 protein was overwhelmingly expressed compared to wild-type and control BOY cells. (C) Cell growth determined by MTT assay. Compared to wild-type and control BOY cells, cell growth was significantly reduced in the COL1A2 transfectant (p<0.0001 day 2, 3, 4 and 5). (D) Percentage of wound closure corresponds to the distance between wound edges in at least three randomly chosen regions (mean \pm SD) relative to the distance at time $0 \mathrm{~h}$ for each cell. A significant wound healing inhibition was observed in the COL1A2 transfectant after $12 \mathrm{~h}$ ( $\mathrm{p}<0.0016$ ) compared with wildtype and control BOY cells.

demethylating agent, we established a COL1A2 transfectant from the cells. Immunoblotting showed a $210 \mathrm{kDa}$ COL1A2 protein in the COL1A2 transfectant at levels $>400$-fold higher than controls (Fig. 3A). Immunocytochemical examination showed that COL1A2 protein was highly expressed in COL1A2-transfected cells, whereas it was absent in control and wild-type BOY cells (Fig. 3B). To evaluate the relationship between COL1A2 expression and cell growth, we performed MTT assays using COL1A2 transfectant, control and wild-type BOY cells. Three independent MTT assays consistently demonstrated significant growth inhibition in COL1A2 transfectant compared with control and wild-type BOY cells on day 2, 3, 4 and $5(\mathrm{p}<0.0001)$ (Fig. 3C). To examine the cellular migration ability, we performed wound healing assays using COL1A2 transfectant, control and wildtype BOY cells. Three independent wound healing assays showed significant wound healing inhibition in COL1A2 transfectant after $12 \mathrm{~h}$ of treatment $(\mathrm{p}<0.0016)$ (Fig. 3D).

Verification of collagen products in cell culture medium of COL1A2 transfectant and detection of intracellular COL1A1/ COL1A2 mRNA expression in the transfectant. To examine whether induced COL1A2 was secreted to extra-cellular matrix (ECM), collagen products of the transfectant was assayed by pepsin treating medium and separated on SDS gel electrophoresis. We found both collagen chain $(\alpha 1$ and $\alpha 2)$ were secreted to the culture medium of COL1A2 transfectant, whereas no collagen chain was detected in that of the control 
(A)

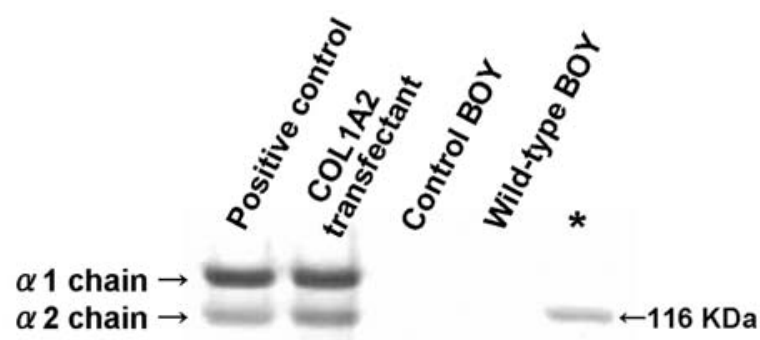

(B)

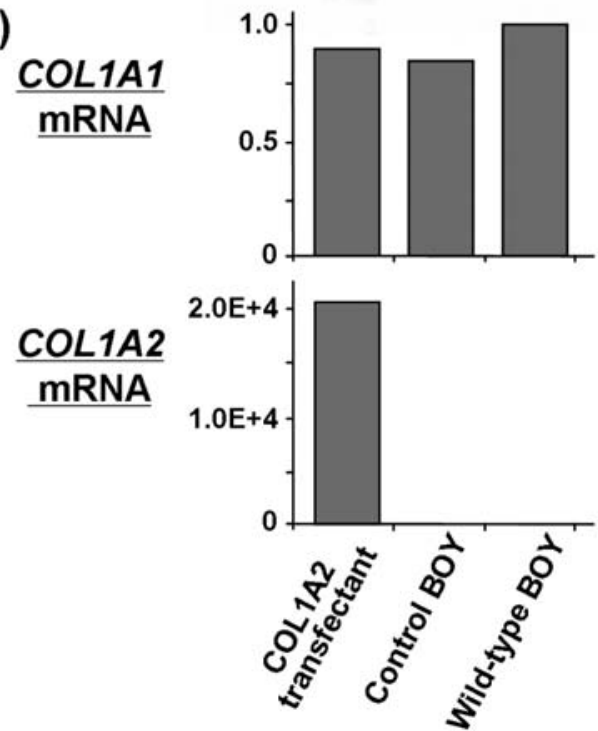

Figure 4. Collagen secretion in cell culture medium of COL1A2 transfectant, control and wild-type BOY cells. (A) $\alpha 1-$ and $\alpha 2$ chain of type I collagen secretion pattern in cell culture medium. Lane 1, positive control; lane 2 , COL1A2-transfected BOY cells; lane 3, cells treated with the control vector; lane 4, wild-type BOY cells. Positive control indicates heterotrimer formation of human type I collagen. *Protein marker. (B) Detection of intracellular COL1A1/COL1A2 mRNA expression of COL1A2 transfectant, control and wild-type BOY cells. Y-axis indicates mRNA expression levels relative to wild-type $\mathrm{BOY}$.

and wild-type BOY cells (Fig. 4A). The ratio of $\alpha 1$ to $\alpha 2$ in secreted collagen of COL1A2 transfectant was close to 2 to 1 ratio, as was the same ratio of the heterotrimer-positive control. We found that mRNA expression of COL1Al was still conserved in COL1A2 transfectant, as was similarly in control or wild-type BOY cells (Fig. 4B, upper). The expression levels of COL1A2 mRNA in COL1A2 transfectant was $\sim 20,000$-fold higher than that in control or wild-type BOY cells (Fig. 4B, lower).

COL1A2 mRNA expression and methylation status of the COL1A2 gene promoter in clinical BC samples. Representative results of MSP and USP assays for COL1A2 in clinical BCs are shown in Fig. 5A. In our series, positive MSP bands were found in 42 of the $67 \mathrm{BCs}(62.7 \%)$ and no visible MSP band was detected in all 10 NBEs (data not shown). Fig. 5B shows typical bisulfite DNA sequencing results for BC samples corresponding to samples ' $U$ ' and ' $P$ ' in Fig. 5A. In sample ' $\mathrm{U}$ ', with a modest USP and no MSP band, there was a modest ' $\mathrm{T}$ ' peak and no ' $\mathrm{C}$ ' peak at each $\mathrm{CpG}$ site (Fig. 5B, upper). In sample ' $\mathrm{P}$ ', with a modest USP and a strong MSP band, there was a modest ' $\mathrm{T}$ ' peak along with a stronger ' $\mathrm{C}$ ' peak at each CpG site (Fig. 5B, lower). We also performed QMSP and real-time quantitative RT-PCR to evaluate the methylation status of the $C O L 1 A 2$ promoter region and the expression levels of COL1A2 mRNA. The methylation index of the BCs was significantly higher than that of the NBEs (BC, 42.3 \pm 28.9 ; NBE, $0.07 \pm 0.01, \mathrm{p}=0.0011$ ) (Fig. $5 \mathrm{C}$, left). In contrast, the COL1A2 mRNA expression level of the BCs was significantly lower than that of the NBEs (BC, 10.1 \pm 2.6 ; NBE, 15.8 \pm 3.8 , $\mathrm{p}=0.0052$ ) (Fig. 5C, right). We found no relationship between the histopathological cancer type and the methylation index or COL1A2 mRNA expression.

\section{Discussion}

A previous study demonstrated a gene expression profile of hypermethylated genes in $\mathrm{BC}$ cells treated with 5-aza-dC with an oligonucleotide microarray (23). However, these gene profiles from specific cancer cells are not always same as those from clinical cancer specimens. The $\mathrm{CpG}$ island array is another tool for high-throughput methylation analysis for detecting the aberrant methylation status of gene promoter in cancer specimens $(4,5)$. However, the protocol for target preparation is complicated. Most of the reported methods are aimed at selective enrichment for the methylated fraction of the genome and use either methylation-sensitive restriction enzymes or antibodies that recognize 5-methyl cytidine $(4,5)$. There are major problems with each reported method. Methods that rely on frequent sites of restriction enzymes (HpaII/ MspI) result in a high genome fraction to be amplified (high complexity), which limits PCR efficiency and ends up favoring non-CpG island DNA. The sensitivity of antibody-based methods is undetermined and possibly low. Finally, there are limited validation data on microarray results for a goldstandard technique (bisulfite-PCR). Thus, false data may lead researchers in the wrong directions. To address these issues, we identified the genes methylated in human BC by filtering the subset of genes restored after 5-aza-dC treatment in human $\mathrm{BC}$ cells from the down-regulated genes in the clinical BCs in our previous microarray (7). Our profile for methylated genes in $\mathrm{BC}$ cells is preferable because we used microarray data from two simple hybridizations. In addition, we confirmed that the promoter hypermethylation of COL1A2, which was at the top of our profile, was significantly frequent in BCs compared to that in NBEs. A significantly higher mRNA expression of COL1A2 was also confirmed in our series of BCs and NBEs. There was no significant relationship in our cohort between the COL1A2 expression and clinicopathological parameters including tumor stage, tumor grade and patient prognosis. Altered expression of the COL1A2 is a frequent event, but it may function early in $\mathrm{BC}$ carcinogenesis.

Previous studies demonstrated that DNA methylation inhibits transcription of COL1A2 promoters $(12,13)$. Consistent with their study, we also found COL1A2 is frequently down-regulated through promoter $\mathrm{CpG}$ hypermethylation in human BC. Previous oligonucleotide microarray analyses showed down-regulation of COL1A2 transcript in some human malignancies, such as $\mathrm{BC}$, hepatoma and malignant melanoma $(7,9,10)$. The functional role of the COL1A2 gene remains controversial. It has been reported as an onco-related molecule as well as a potential tumorsuppressor gene $(12,19)$. What is the significance of decreased collagen synthesis in cancer? Type I collagen consists of a 
(A)

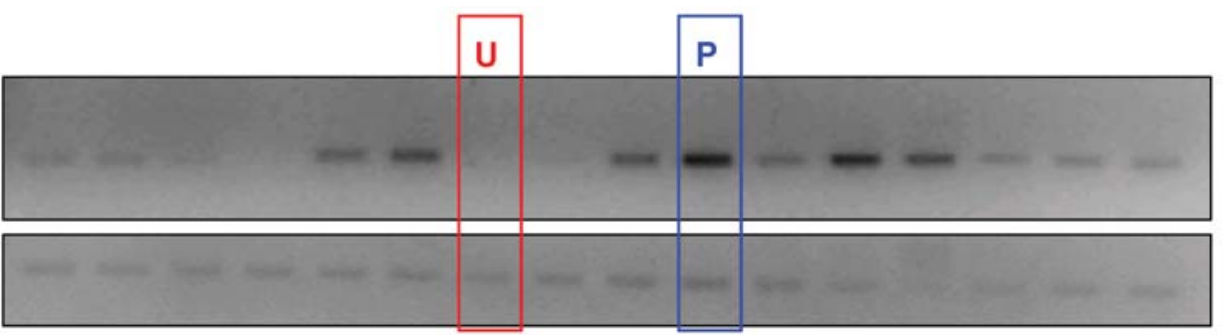

(B)

Bladder cancer (Unmethylated)

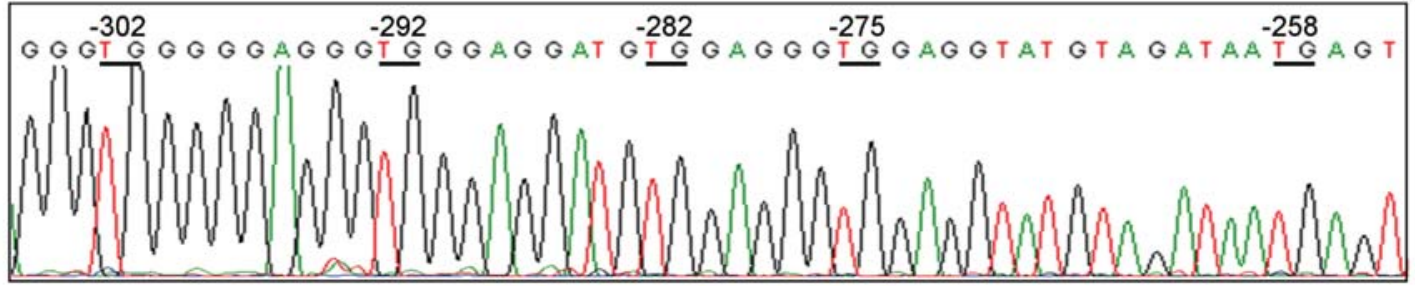

Bladder cancer (Partially Methylated)

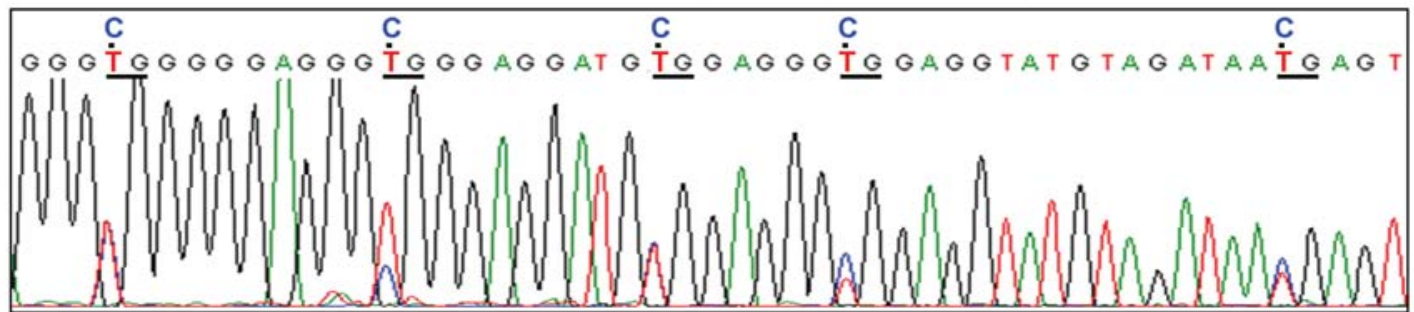

(C)

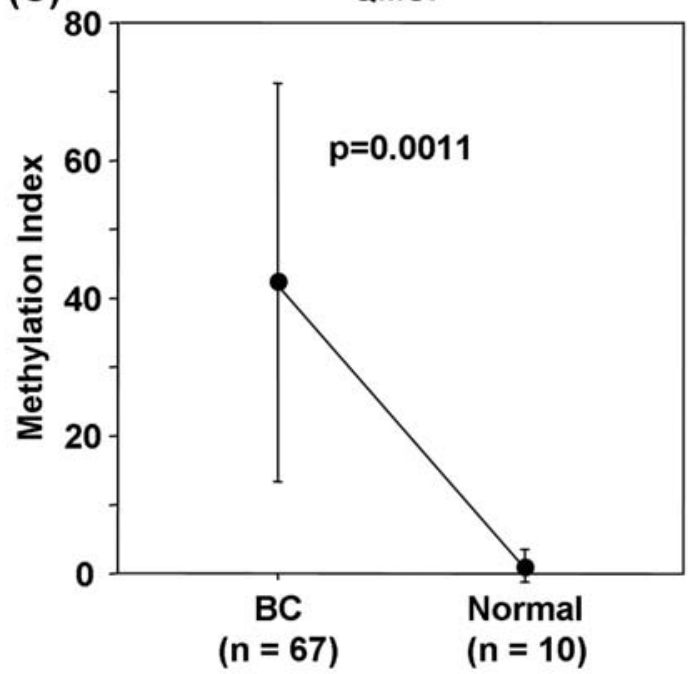

Real time RT-PCR

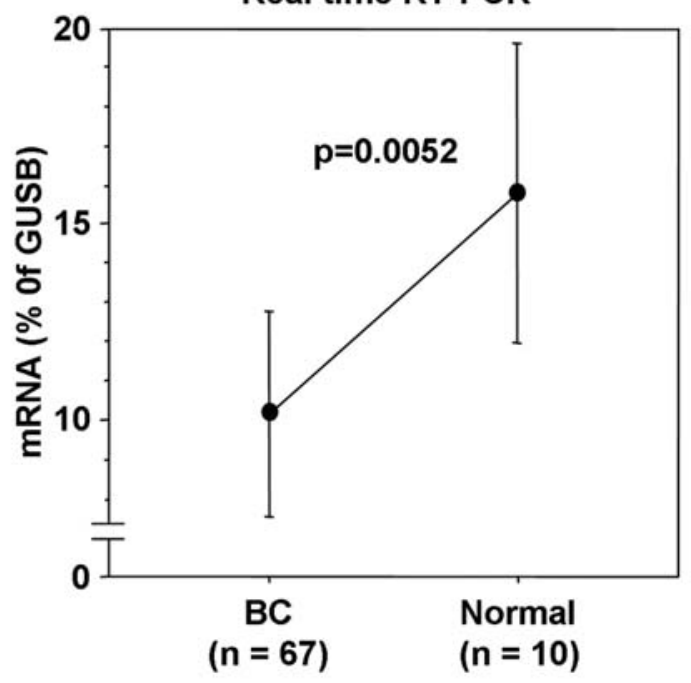

Figure 5. Methylation status of the COL1A2 promoter and COL1A2 mRNA expression in clinical samples. (A) Representative results of MSP (top) and USP (bottom) of BC samples. (B) Bisulfite DNA sequencing of samples with no (sample 'U') and strong (sample 'P') MSP bands. Sample 'U', which manifested no MSP and a modest USP band, exhibited a very low ' $\mathrm{C}$ ' peak along with a modest ' $\mathrm{T}$ ' peak at each CpG site (top). Sample 'P', which manifested a strong MSP and a modest USP band, exhibited a stronger ' $\mathrm{C}$ ' peak along with a modest ' $\mathrm{T}$ ' peak at each CpG site (bottom). PCR conditions and primer sequences are listed in Table II. (C) The COL1A2 methylation index was significantly higher in the BCs than NBEs (p=0.0011) (left). Conversely, COL1A2 mRNA expression was significantly lower in the BCs than NBEs ( $\mathrm{p}=0.0052)$ (right).

heterotrimer with two similar procollagens: $\alpha 1$ chains (COL1A1) and $\alpha 2$ chain (COL1A2). In our profile, COL1A1 and COL1A2 are the top 2 up-regulated mRNA transcripts after treatment of the demethylating agent. Simultaneous inactivation of both genes by promoter methylation results in low expression levels of type I collagen protein, the major fibrillar component of the stroma. However, previous studies suggest that these procollagens may function independently regardless of a heterotrimer structure $(12,15)$. Some investi- gators have reported that repression of the COL1A2 protein due to hypermethylation of the gene promoter was observed in tumorigenic cell lines $(11,13)$. Moreover, stable transfectant of the COL1A2 in a tumorigenic cell line showed a flatter morphology with increased adherence to the substratum, a reduced ability to proliferate in soft agar, slower growth kinetics and suppression of tumorigenicity $(12,15)$. Other investigators have demonstrated that decreased collagen production by tumorigenic cells correlates with faster cell 
growth, less adhesion to substratum and increased tumorigenicity of the transformed cells $(16,17)$. However, in some malignancies, COL1A2 is overexpressed and plays a role in tumor development through angiogenesis and interactions with integrin or TGF- $\beta$ signaling pathways $(18,19)$. To analyze the functional consequences of COL1A2 silencing in BC cells, we established a stable COL1A2 transfectant. Our cell proliferation assays consistently demonstrated growth inhibition in the COL1A2 transfectant compared with control and wild-type BC cells. Wound healing assays showed significant wound healing inhibition in the COL1A2 transfectant. Our collagen analysis revealed that heterotrimer collagen was produced in cell culture medium of the COL1A2 transfectant. Because we detected COLIAl mRNA expression inherent in COL1A2 transfectants as well as wild-type, induced COL1A2 seems to be secreted as heterotrimer formation (two $\alpha 1$ - and one $\alpha 2$-chain) by coupling with COL1A1. Consistent with a previous study (12), these results suggest that cell growth- and migration inhibition may caused by increased cell adhesion to the heterotrimer collagen secreted in ECM of the COL1A2 transfectant. Hence, decreases in collagen production contribute to the tumorigenic phenotype by changing the cell matrix interactions. However, functional roles of the procollagen intracellular still remains to be elucidated. Further experiments will determine whether COL1A2 suppresses intracellular signal transduction pathways for tumorigenicity. In our clinical samples, we found no relationship between the histopathological cancer type and the methylation index or COL1A2 mRNA expression. The cohort includes many samples from TUR-Bt. Pathological diagnosis regarding tumor stage or grade tends to be incorrect because of the tissue degradation by electric coagulation. It may influence statistical accuracy. To our knowledge, we demonstrated for the first time the silencing of COL1A2 in $\mathrm{BC}$ cells. We conclude that the mechanism of COL1A2 down-regulation in $\mathrm{BC}$ cells is through $\mathrm{CpG}$ hypermethylation of the promoter region. The fact that restored COL1A2 expression in the transfectant decreased cell growth and migration activity indicates that COL1A2 is a promising candidate for gene therapy of human $\mathrm{BC}$.

\section{Acknowledgements}

This study was partially supported by the Ministry of Education, Science, Sports and Culture, Grant-in-Aid for Scientific Research (C), 18591761, 2006; (B), 20390427, 2008; and (C), 20591861, 2008. We thank Ms. Mutsumi Miyazaki for her excellent laboratory assistance.

\section{References}

1. Jemal A, Siegel R, Ward E, et al: Cancer statistics, 2008. CA Cancer J Clin 58: 71-96, 2008.

2. Mitra AP, Datar RH and Cote RJ: Molecular pathways in invasive bladder cancer: new insights into mechanisms, progression, and target identification. J Clin Oncol 24: 5552-5564, 2006.
3. Ushijima T: Detection and interpretation of altered methylation patterns in cancer cells. Nat Rev Cancer 5: 223-231, 2005.

4. Lippman Z, Gendrel AV, Black M, et al: Role of transposable elements in heterochromatin and epigenetic control. Nature 430: 471-476, 2004.

5. Rauch T, Li H, Wu X and Pfeifer GP: MIRA-assisted microarray analysis, a new technology for the determination of DNA methylation patterns, identifies frequent methylation of homeodomain-containing genes in lung cancer cells. Cancer Res 66: 7939-7947, 2006

6. Estécio MR, Yan PS, Ibrahim AE, Tellez CS, Shen L, Huang TH, et al: High-throughput methylation profiling by MCA coupled to CpG island microarray. Genome Res 17: 1529-1536, 2007.

7. Kawakami K, Enokida H, Tachiwada T, et al: Identification of differentially expressed genes in human bladder cancer through genome-wide gene expression profiling. Oncol Rep 16: 521-531, 2006.

8. Heino J: The collagen family members as cell adhesion proteins. Bioessays 29: 1001-1010, 2007

9. Chiba T, Yokosuka O, Fukai K, et al: Identification and investigation of methylated genes in hepatoma. Eur J Cancer 41: 1185-1194, 2005.

10. Muthusamy V, Duraisamy S, Bradbury CM, et al: Epigenetic silencing of novel tumor suppressors in malignant melanoma. Cancer Res 66: 11187-11193, 2006.

11. Sengupta PK, Smith EM, Kim K, Murnane MJ and Smith BD: DNA hypermethylation near the transcription start site of collagen alpha2(I) gene occurs in both cancer cell lines and primary colorectal cancers. Cancer Res 63: 1789-1797, 2003.

12. Lim A, Greenspan DS and Smith BD: Expression of alpha 2 type I collagen in W8 cells increases cell adhesion and decreases colony formation in soft agar. Matrix Biol 14: 21-30, 1994.

13. Smith BD and Marsilio E: Methylation of the alpha 2(I) collagen gene in chemically transformed rat liver epithelial cells. Biochem J 253: 269-273, 1988.

14. Parker MI, Judge K and Gevers W: Loss of type I procollagen gene expression in SV40-transformed human fibroblasts is accompanied by hypermethylation of these genes. Nucleic Acids Res 10: 5879-5891, 1982.

15. Travers H, French NS and Norton JD: Suppression of tumorigenicity in Ras-transformed fibroblasts by alpha 2(I) collagen. Cell Growth Differ 7: 1353-1360, 1996.

16. Rowe DW, Moen RC, Davidson JM, Byers PH, Bornstein P and Palmiter RD: Correlation of procollagen mRNA levels in normal and transformed chick embryo fibroblasts with different rates of procollagen synthesis. Biochemistry 17: 1581-1590, 1978.

17. Sandmeyer S, Smith R, Kiehn D and Bornstein P: Correlation of collagen synthesis and procollagen messenger RNA levels with transformation in rat embryo fibroblasts. Cancer Res 41: 830-838, 1981.

18. Liang Y, Diehn M, Bollen AW, Israel MA and Gupta N: Type I collagen is overexpressed in medulloblastoma as a component of tumor microenvironment. J Neurooncol 86: 133-141, 2008.

19. Yang S, Shin J, Park KH, et al: Molecular basis of the differences between normal and tumor tissues of gastric cancer. Biochim Biophys Acta 1772: 1033-1040, 2007.

20. Sobin LH and Wittekind C: TNM Classification of Malignant Tumours. In: International Union Against Cancer (UICC). 6th edition. Wiley-Liss Publications, New York, 2002.

21. Takemoto M, Shirahama T, Miyauchi T, et al: Metanestin, a glycoprotein with metastasis-associated expression in transitional cell carcinoma of the urinary bladder. Int $\mathrm{J}$ Cancer 74: 7-14, 1997.

22. Guenette DK, Ritzenthaler JD, Foley J, Jackson JD and Smith BD: DNA methylation inhibits transcription of procollagen alpha 2(I) promoters. Biochem J 283: 699-703, 1992.

23. Wu G, Guo Z, Chang X, et al: LOXL1 and LOXL4 are epigenetically silenced and can inhibit ras/extracellular signalregulated kinase signaling pathway in human bladder cancer. Cancer Res 67: 4123-4129, 2007. 